\title{
Determinants of visits of cancer patients to Dutch Community Based Psychosocial Support Centres (CBPSCs)
}

\section{Adriaan Visser, $\mathrm{PhD}$, health psychologist ${ }^{\star}$}

Employed at the Rotterdam Applied University, Centre of Expertise for Innovations in Care, Rotterdam, the Netherlands during the study. Currently director and researcher at PRO-health.org, Rotterdam, the Netherlands.

\section{Corresponding authors}

Dr Adriaan Visser, PRO-health.org; Abraham Kuyperlaan 91A; 3038 PG, Rotterdam, the Netherlands; adriaan.visser@planet.nl

Submitted: 11 March2021;Accepted:18 March 2021;Published: 01 Apr 2021

Citation: Adriaan Visser (2021) Determinants of visits of cancer patients to Dutch Community Based Psychosocial Support Centres (CBPSCs). Medical \& Clinical Research 6(4): 474-481.

\begin{abstract}
Aim: The psychosocial support for cancer patients in the mental health care is often limited because of difficulties in access and the expense to patients. In response, informal regional support centers have been developed in the Netherlands called "Community-based Psychosocial Support Centres (hereinafter: CBPSCs) for cancer patients and relatives. They offer supporting complementary activities and professional psychological help which are easily accessible and free of charge. We studied the use (frequency, duration and future use) and the determinants of the visits to CBSPCS.

Method: Visitors covering 701 cases from 25 CBPSCs filled-out a web-based questionnaire, answering questions about how often they contacted CBPSCs (frequency, duration and future use) and which personal factors, mainly based of the ASE model, influenced the use of CBPSCs. Also, the well-being of the patient, the evaluation of the visits and the significance of the support received were studied as dependent variables, in addition to the role of the ASE factors, applying multivariate analyses. All sum scores showed a strong internal consistency.

Results: Most patients did not know what CBPSCs are or where to find them. About one-fifth was alerted by family, friends and acquaintances. Another 20\% was informed about CBPSCs by hospital oncology nurses and through leaflets. Patients rarely reported being referred by their GPs and medical specialists. Health care providers in hospitals were much better informed about CBPSCs, referring approximately half of their patients to CBPSCs. Around two thirds of the patients visited the CBSPC once a week for 2 to 3 hours and intended to continue these visits in years to come. Present use generally showed that the most important determinants are the attitude towards the visits, whether the patient is a recent visitor, the patient's perceived significance of the visits and having a socially-inactive lifestyle.
\end{abstract}

Conclusions: The study confirms the high value that this type of organisation provides in informal support in cancer care. The CBPSCs need to improve their visibility in the healthcare system through more public campaigns and better information to patients. More countries should introduce and stimulate this type of easily-accessible, cheap, effective and highly-valued supportive care centres, and explore the needs of patient and family members.

Keywords: Cancer, Use and Determinants, Community-Based Support Centres in Cancer, The Netherlands.

\section{Introduction}

Due to a national higher life expectancies and aging populations in several countries the number of people with cancer is increasing [1]. Prevalence statistics? from 2019 show that 578,000 people in the Netherlands are diagnosed with cancer [2]. Patients and providers report that the diagnosis of cancer and the ensuing treatment may influence their lives as both patient and relative, in practical, physical, emotional, social, and spiritual terms. This emotional situation, which is frequently severe, stresses the importance of appropriate and easily-accessible psychosocial care and aftercare for cancer patients and their family members [3-5].
Organisation of Psychosocial Supportive Care

The development of adequate psychosocial support for cancer patients is an important organisational task in the healthcare [3-5]. Cancer patients and their relatives may receive support in hospitals from the direct involved oncologists and oncology nurses, however, they often have limited availability due to their work overload. The primary healthcare system has broadened the psychosocial support possibilities that can be provided by general practitioners (GPs), social workers, psychologists, and psychiatrists. Due to organisational factors such as waiting lists and financial restrictions, the forms of psychosocial supportive care mentioned 
above are often not easily accessible to cancer patients. For this reason, patient organisations, often in cooperation with healthcare professionals, have taken the initiative to establish patient-oriented support centres in several countries. Examples of these centres are the Maggie's Centres in the UK, Barcelona and Hongkong and in the USA, the MD Anderson Cancer Centre (Houston) and the Memorial Sloan Kettering Cancer Center (New York) all offering support groups. In Germany, the psychological support is organised by the Lenser Institute (Life-valued Institute) in Cologne and by the Krebsgesellschaft (Cancer Society) in Bavaria (München). Comparable initiatives exist in Australia, Belgium, Canada, Denmark, Norway and Israel $[6,7]$. In the Netherlands, it was primarily both former and current cancer patients who took the initiative to establish CBPSCs, community-based psychosocial support centres for cancer patients and their family members [8].

\section{The focus of CBPSCs}

The Dutch CBPSCs are private initiatives, set up as independent social enterprises that are funded by local and national policymakers, sponsorships, grants, donations and centre-organized activities. During the study, more than 40,000 cancer patients and relatives visited the CBPSCs [1]. These centres are often led by a part-time, paid professional director or coordinator, in addition to the organisational support of the specialized trained volunteers. The support that CBPSCs offer to their visitors can range from participation in social activities to receiving therapeutic psychosocial support [8].

Social activities are low-threshold psychosocial support facilities, offering contact with fellow patients who have or have had cancer and are dealing with their illness, treatment and care. It may include personal meetings with fellow patients (e.g., mornings to have a cup of coffee together), discussion groups, informal talks, creative expression (painting, photography) and body-mind activities for relaxation (meditation, singing).

Therapeutic support includes psychological therapy given by professionals within CBPSC's or other outside professionals working closely with the CBPSCs. Such therapy offers cognitive behaviour therapy (CBT), yoga, mindfulness training and forms of individual and group therapeutic coaching.

The role and support offered by CBPSCs are a part of the whole psychosocial oncology care, which acts as the lowest level of organized support in a stepped-care model [8]. This may lead to a more convenient availability of informal care and support to cancer patients, closer to home [9]. This requires, however, appropriate and adequate referrals from the healthcare system, as well as informed choices by patients. The lack of information about these requirements was the impetus for our study.

\section{Aims of the Study}

At the start of the foundation and development of CBPSCs, little information was available about how and why cancer patients choose the CBPSCs, because they were rather new facilities. We studied the level of use (frequency, duration and future use) as well as which factors influenced their choice for CBPSCs.

\section{Material and Methods}

We studied the use of CBPSCs services by cancer patients, by filling out a web-based questionnaire. Thirty centres were included in this study, using approximately half of the 60 CBPSC centres that were available and willing to participate, with data based on the visitors from eight years ago. Five CBPSCs could not participate due to practical reasons. Patients from 25 CBPSCs were invited by email, post and flyers. In total, 3,134 invitations were sent, 2,436 by email and 698 by regular mail. In total, 701 visitors of 790 participants decided to participate in this part of the study (a drop-out rate of $11 \%)$.

\section{The Questionnaire}

The questions focused on the use of the centres and the factors influencing the choice made by cancer patients to visit CBPSCs. The use was studied with questions about the frequency of the visits, the duration of the visits and planned future visits. The determinants studied included:

a. Social background factors, e.g., gender, education, recent or more long-term visitors and age.

b. Medical condition such as severity and type of cancer, comorbidities, present treatment, use of alternative medicine (CAM).

c. Attitude, perceived social norms and self-efficacy toward the use, based on the ASE model.

d. Quality of life, complaints, and the burden of the cancer and its treatment as experienced by the patient.

e. Perceived stress and feelings after the visits.

f. Evaluation of the support and therapy received such as satisfaction and supply of information.

These factors are integrated in the ASE model, as the explanatory model driving health behaviours. The usability and validity of the questions were proved in former studies $[8,10,11]$. Based on the ASE model adapted the general attitude towards CBPSCs was measured by 5 questions, the perceived expectations of the social environment (family, friends, oncologists) and the experienced efficacy (e.g., how to reach a CBPSC, and the health condition of the patients) [12].

\section{Statistical Analysis}

For the construction of the scales, we checked the reliability by Cronbach's alpha coefficients. We used mainly Pearson correlation coefficients and multivariate analyses e.g., factor analysis to study the correlations between the determinants (see the measured indicators above) and the dependent variables. This was also applied to dichotomy variables. We applied SPSS in all analyses [13].

\section{Ethical approval}

To guarantee ethical procedures both the members of the advisory board and the scientific committee of the Dutch Cancer Society approved our research protocol.

\section{Results}

\section{The Measurements}

In table 1 all the developed scales and single item determinants are presented, including the numbers of questions. All constructed 
indicators have a high internal consistency, indicated by the Cronbach's alpha coefficient. The information about the direction of the measurement is important to the interpretation of results to be reported later.

The use of CBPSCs

Most of the cancer patients who visited a CBPSC did not know what a CBPSC was and had not been informed about how to find a
CBPSC in their region [8]. The largest group of visitors answered that they were alerted about a local CBPSC by family, friends and acquaintances (22\%). Furthermore, information from hospital oncology nurses and leaflets each account for $21 \%$ of patients who learned of the existence of CBPSCs. Referrals by health care professionals from primary and secondary health care were rarely mentioned: medical specialists $(6 \%)$ and general practitioners $(5 \%)$.

Table 1: Information about the measurements.

\begin{tabular}{|c|c|c|c|c|}
\hline & $\begin{array}{l}\text { Number } \\
\text { of items }\end{array}$ & $\begin{array}{l}\text { Scale } \\
\text { range }\end{array}$ & $\begin{array}{c}\text { Number of } \\
\text { patients }\end{array}$ & $\begin{array}{c}\text { Alpha Score } \\
\text { coefficient direction }\end{array}$ \\
\hline I.BACKGROUND FACTORS & & & & N.A \\
\hline Type visit ( $0=$ family, $1=$ self $)$ & 1 & $1-2$ & $1-2$ & \\
\hline Gender $(1=$ woman; 2 = man $)$ & 1 & $1-2$ & 711 & \\
\hline Education level (three levels) & 1 & $1-3$ & 701 & \\
\hline Age & 1 & $1-4$ & 707 & \\
\hline Social status: active $(=1)$; not active $(=2)$ & 1 & $1-2$ & 702 & \\
\hline Experienced visitor (long ago 1; recent $=2$ ) & 1 & $1-2$ & 704 & \\
\hline \multicolumn{5}{|l|}{ II.MEDOCAL CONDITION } \\
\hline Severity $($ less severe $=1 ;$ more severe $=2)$ & 1 & $1-2$ & 621 & \\
\hline Type of cancer: breast cancer $=1$, other $=0$ & 1 & $1-0$ & 621 & \\
\hline Diagnosis shorter than 3 years ago $=1$, longer ago $=2$ ) & 1 & $1-2$ & 621 & \\
\hline Comorbidities $($ no $=0$, yes $=1)$ & 1 & $1-0$ & 621 & \\
\hline Current med, treatment $($ not $=1$, under control $=2$, regular treatment $=3$ ) & 1 & $1-3$ & 621 & \\
\hline Use of alternative therapies outside the CBPSC) $($ not $=0$, yes $=1)$ & 1 & $0-1$ & 621 & \\
\hline \multicolumn{5}{|l|}{ III. EVALUATION ACTIVTITIES } \\
\hline Evaluation activities & 1 & $1-10$ & 659 & N.A \\
\hline Support during activities & 5 & $1-5$ & 614 & 89 \\
\hline Informatie supply & 4 & $1-4$ & 639 & 76 \\
\hline \multicolumn{5}{|l|}{ IV.EVALUATION THERAPIES } \\
\hline Evaluation therapy & 1 & $1-10$ & 139 & N.A \\
\hline Evaluation therapist & 5 & $1-4$ & 136 & 93 \\
\hline Information supply by therapist & 4 & $1-4.84$ & 133 & 84 \\
\hline \multicolumn{5}{|l|}{ V.ATTITUDE ,PERCEIVED NORMS, SELF-EFFICACY (ASE-MODEL) } \\
\hline Attitude & 5 & $1-4$ & 661 & 87 \\
\hline Social norms & 6 & $1-4$ & 559 & 91 \\
\hline Self-efficacy & 4 & $1-4$ & 599 & 86 \\
\hline \multicolumn{5}{|l|}{ ***VI MEANING OF THE SUPPORT } \\
\hline Perceived gain & 9 & $1-4$ & 568 & 94 \\
\hline Feelings after the visit & 10 & $1-3$ & 469 & 72 \\
\hline V.EVALUATION OF CBPSCs & 4 & $1-10$ & 698 & 93 \\
\hline \multicolumn{5}{|l|}{ VI.EXPERCIENCED WELL-BEING } \\
\hline General quality of life & 3 & $1-7$ & 602 & 94 \\
\hline Complains & 10 & $1-4$ & 569 & 87 \\
\hline Burden of the illness & 4 & $1-10$ & 610 & 84 \\
\hline
\end{tabular}


Once patients have found their way to a CBPSC, they visit the CBPSC once a week $(28 \%)$ or more frequently $(10 \%)$. A third (34\%) visits the CBSC once or several times a month. A visit lasts about 2 to 3 hours. Almost half (44\%) of the visitors want to continue visiting the CBPSCs in the coming years. Two thirds $(69 \%)$ of the visitors report that they have been visiting the CBPSC for more than a year. Most visitors only contemplate stopping their visits to the CBPSC when their health circumstances require that.

\section{Correlations with Behavioural Factors}

We studied the correlations between the independent factors with the frequency, the duration of the visits and the planned future visits. The three dependent variables are correlated (table 2). This shows that the frequency of the visits is an indicator of the duration of the visits and the frequency of the future visits. The correlations between the behavioural aspects and the visits indicators are presented in table 3 .

Table 2: Correlations between the behavioural aspect of the visits.

\begin{tabular}{|l|l|l|l|}
\hline & Frequency of visits $\mathbf{N}=\mathbf{7 0 5}$ & Duration of visits $\mathbf{N}=\mathbf{6 9 9}$ & Intended future visits $\mathbf{N}=\mathbf{7 0 1}$ \\
\hline Frequency of visits & ------- & $.45^{*}$ & $.58^{*}$ \\
\hline Duration of visits & & - &, $46^{*}$ \\
\hline Intended future visits & & & - \\
\hline
\end{tabular}

$* p<.001$

The data in table 3 show that the frequency of the visits is higher in cases of lower social status, higher evaluation of the activities and support, positive attitude towards CBPSC, general evaluation of the CBPSC, perceiving more gain from the visits, positive feelings after the visits and a heavier burden of the illness.
The duration of the visits is longer in cases of being a cancer patient, socially inactive, a higher evaluation of the activities and support, general evaluation of the CBPSC, perceiving more gain from the visits, positive feelings after the visits, and a heavier burden of the illness. 
Table 3: Correlation between the independent factors and the visit indicators: frequency, duration and intended visits, (Pearson correlation coefficients).

\begin{tabular}{|c|c|c|c|}
\hline & $\begin{array}{l}\text { Frequency } \\
\text { of visits }\end{array}$ & $\begin{array}{l}\text { Duration of } \\
\text { visits }\end{array}$ & $\begin{array}{l}\text { Intended future } \\
\text { visits }\end{array}$ \\
\hline \multicolumn{4}{|l|}{ I. BACKGROUND FACTORS } \\
\hline Type visit ( $0=$ family, $1=$ self $)$ &, 065 &, $079 *$ &, $162 *$ \\
\hline Gender $(1=$ woman; $2=$ man $)$ &, 009 &,- 001 &, 034 \\
\hline Education level (three levels) &,$- 090 *$ &,- 061 &,- 048 \\
\hline Age &, 074 &,- 042 &,- 013 \\
\hline Social status: active $(=1)$; inactive $(=2)$ &, $136 * *$ &, $080 *$ &, $126 * *$ \\
\hline Experienced visits (long ago 1 ; recent $=2$ ) &, 052 &, 015 & ,001 \\
\hline \multicolumn{4}{|l|}{ II. MEDICAL CONDITION } \\
\hline Severity $($ less severe $=1 ;$ more severe $=2)$ &, 038 &,- 028 &,- 056 \\
\hline Type of cancer: breast cancer $=1$, other $=0$ &,- 032 &, 011 &, 024 \\
\hline Diagnosis shorter than 3 years ago $=1$, longer ago $=2$ ) &,- 012 &,- 009 &,- 038 \\
\hline Comorbidities $($ no $=0$, yes $=1)$ &, 021 &,- 011 &, 048 \\
\hline Current medical treatment (none $=1$, under control $=2$, regular treatment $=3$ ) & ,068 &, 130 &, 104 \\
\hline Use of alternative therapies outside the CBPSC) $($ none $=0$, yes $=1)$ &, 033 & 059 & ,024 \\
\hline \multicolumn{4}{|l|}{ III. EVALUATION ACTIVTITIES } \\
\hline Evaluation activities &, $197 * *$ &, $189 * *$ &, $164 * *$ \\
\hline Support during activities &, $145^{* *}$ &, $106 * *$ & ,098* \\
\hline Information supply &, 052 &,- 014 & 003 \\
\hline \multicolumn{4}{|l|}{ IV.Evaluation therapies } \\
\hline Evaluation therapy &, 026 &, 026 &,- 025 \\
\hline Evaluation therapist &,- 082 &,- 021 &,- 122 \\
\hline Information supply by therapist &,- 044 &,- 040 &,- 010 \\
\hline \multicolumn{4}{|l|}{$\begin{array}{l}\text { V. ATTITUDE, PERCEIVED NORMS, SELF-EFFICACY (ASE- } \\
\text { MODEL) }\end{array}$} \\
\hline Attitude &, $398 * *$ &, $247 * *$ &, $319 * *$ \\
\hline Social norm &, 029 &, 042 &, 075 \\
\hline Self-efficacy &, 013 &, 001 &,- 024 \\
\hline \multicolumn{4}{|l|}{ VI MEANING OF THE SUPPORT } \\
\hline Perceived gain & $263 * *$ &, $162 * *$ &, $119 * *$ \\
\hline Feelings after the visits &, $187 * *$ &, $176^{* *}$ &, $254 * *$ \\
\hline EVALUATION OF CBPSC &, $245 * *$ &, $207 * *$ &, $182 * *$ \\
\hline \multicolumn{4}{|l|}{ VI.EXPERCIENCED WELL-BEING } \\
\hline General quality of life &,- 039 &,- 064 &,- 043 \\
\hline Complaints &, 072 &, 088 &, 085 \\
\hline Burden of the illness &, $116^{* *}$ &, $102 *$ &, $109 * *$ \\
\hline
\end{tabular}

$* p<.05 ; * * p<.01$ 
The future use is mainly correlated with being a cancer patient, socially inactive, higher evaluation of the activities and support, general evaluation of the CBPSC, perceiving more gain from the visits, positive feelings after the visits, a heavier burden of the illness.

Given several of the indicators mentioned in table 3, a regression analysis was conducted in order to explore which factors influence the behaviours (Method Enter). If we take the frequency of visits as the main independent variable, then the analyses show that the attitude towards the visits, being a recent visitor and a less active social life are the most important determinants. The explained variance of this model is $30 \%$.

\section{Other Dependent Variables}

In addition to the direct behavioural aspects as mentioned above, there may also be more indirect indicators of the patient's behaviours. In this context, we studied the correlation with the patient's well-being, the evaluation of the CBPCs and the social support received.

\section{Correlations with Patient's Well-Being}

The correlation was studied between the independent behavioural indicators and four aspects of the well-being: feelings after the CBPSC visit, general quality of life, complaints and burden of the illness. Table 4 shows the correlation between the well-being indicators. The three indicators of the patient's well-being are correlated, but the correlations are not so strong to construct one well-being score.

Table 4: Correlation between the well-being measurements

\begin{tabular}{|l|l|l|l|}
\hline & $\begin{array}{l}\text { Quality of life } \\
\mathbf{N}=\mathbf{6 0 2}\end{array}$ & $\begin{array}{l}\text { Complaints } \\
\mathbf{N}=\mathbf{5 6 4}\end{array}$ & $\begin{array}{l}\text { Burden of } \\
\text { illness N=600 }\end{array}$ \\
\hline Quality of life & - & $-.635^{* *}$ &,$- 454^{* *}$ \\
\hline Complaints & & & \\
\hline $\begin{array}{l}\text { Burden of the } \\
\text { illness }\end{array}$ & & - & $.649^{* *}$ \\
\hline
\end{tabular}

$* p<.05, * * P<.01$

The correlations with the patient's well-being indicators are presented elsewhere [14]. A regression analysis shows that for the general quality of life, the following factors are the independent determinants: positive feelings after the CBPSC visits, selfefficacy, the severity of the illness, comorbidities, and the attitude towards the visits. The explained variance is $22 \%$.
Correlation with evaluation of the CBPSC.

The three indicators of the evaluation are quite high (see table 5 ). The correlations with the independent factors are presented elsewhere [14]. Regression analysis show that that the evaluation of the activities (highest $\mathrm{N}$ ) is mainly influenced by the attitude toward the CBPSC, the perceived gain from the visits and positive feeling after the visit. This model explains $24 \%$.

Table 5: Correlations between the evaluation measures.

\begin{tabular}{|l|l|l|l|}
\hline & $\begin{array}{l}\text { Evaluation of the activities } \\
\mathbf{N}=\mathbf{6 5 9}\end{array}$ & $\begin{array}{l}\text { Evaluation of the therapy } \\
\mathbf{N}=\mathbf{1 3 6}\end{array}$ & $\begin{array}{l}\text { Positive aspects of the } \\
\text { CBPSC } \\
\mathbf{N}=\mathbf{6 5 2}\end{array}$ \\
\hline Evaluation of activities & - & $.575^{* *}$ & $.672^{* *}$ \\
\hline Evaluation of therapy (if present) & & - &, $516^{* *}$ \\
\hline Positive aspects of the CBPSC & & & - \\
\hline
\end{tabular}

$* p<.05, * * p<.01$

\section{The Meaning of the Support}

The significance of the support experienced may be important to the continuation of the visits. That significance is measured by the gain that patients experienced from the visits, e.g., having a better grip on one's own feelings, the exploration of the significance of the cancer, respect of boundaries, personal development (in total 9 items) and the feelings after the visits (10 items). Both factors correlate $\mathrm{r}=.33, \mathrm{p}<.001$. The correlations with the independent variable are presented elsewhere [14].The regression analysis shows that the following factors are the main determinants: not actively work/unemployed, less severe condition of the illness,

intention to visit the CBPSC in the future, positive evaluation of the activities and a positive attitude towards the CBPSC. The explained variance of this model is $52 \%$.

The Role of the ASE factors

The attitude, the perceived social norms and the efficacy are 
potential determinants of the visitors' behaviour (ASE model). Two the three indicators are collated, as shown in table 6. Self-efficacy is not correlated with social norms.

Table 5: Correlation between attitude, perceived social norms and self-efficacy.

\begin{tabular}{|l|l|l|l|}
\hline & $\begin{array}{l}\text { Attitude } \\
\mathbf{N}=\mathbf{6 6 1}\end{array}$ & $\begin{array}{l}\text { Social norm } \\
\mathbf{N}=\mathbf{5 5 9}\end{array}$ & $\begin{array}{l}\text { Self-efficacy } \\
\mathbf{N}=\mathbf{5 9 9}\end{array}$ \\
\hline Attitude & - & $.268^{* *}$ & $.151^{* *}$ \\
\hline Social norm & & - &, 025 \\
\hline Self-efficacy & & & - \\
\hline
\end{tabular}

$* p<.05, * * p<.01$

The regression analysis show that attitude is mainly correlated with the perceived significance of the visits, having paid employment, evaluation of the CBPSC, frequency of visits to the CBPSC and the planned future visits. The explained variance of this model is $52 \%$, showing that the ASE factors are important determinants of the behavioural indicators.

\section{Conclusion and Discussion Conclusion}

Adequate social support for cancer patients is an organizational task for healthcare. This requires a patient-centered approach which is often not very well developed in healthcare for cancer patients. Consequently, cancer patients frequently struggle to find appropriate psychosocial oncological care, within the often medical-technically and not psychosocially-oriented medical care [15-17]. Dutch psychosocial cancer healthcare tried to solve this problem through the foundation of community-based support centres for cancer patients (CBPSCs). In a quantitative study, we explored which factors influence the frequency of the visits, how cancer patients came in contact with CBPSCs and how the referral process within healthcare functions.

The study showed that the greatest number of visitors are rarely referred through the healthcare system but that this occurred through informal contacts of the patients themselves, because CBPSCs were rather unknown in the healthcare system. The patients who were referred participated in a lot of supportive social activities and used therapeutic activities within a broad range of therapies. The main determinants of the number of visits were the attitude towards the CBPSC, being a recent visitor, having a less active social life, and the significance of the visits.

\section{Discussion}

This is the first extensive study on the organization of CBPSCs in the Netherlands. It confirms the results of earlier smaller studies [10]. The number of participants in our study was lower than expected, because we intended to include the number of visitors, whilst the CBPSCs often count the number of visits. The patient sample is possible biased by the participation of a large number of women with breast cancer and a smaller number of men with prostate cancer, as compared to national statistics [2]. The limitations of the cross-sectional survey method in this study are compensated by a more qualitative study on the factual reported supplied care by oncological providers [15]. However, our study cannot (yet) prove cause and effects relations.
Referrals to CBPSCs is rather limited in the healthcare system, especially referrals by oncologists, medical doctors or GPs. Other, and more recent studies show that this situation has not improved much [18, 19]. An effective Public Relations campaign for CBPSCs should especially be concentrated in hospitals and the primary healthcare system, to improve their visibility and make them more well-known to the public. In the meantime, the number of Dutch CBPSCs is rising, but the finances are still limited.

\section{Practical Implications}

The study also implies lessons for the psychosocial cancer in other countries. Since conducting this study, a few other countries have introduced and implemented similar organizations like the CBPSCs. Meanwhile, there is a growing interest for the foundation of comparable support centers in other countries [6, 7]. However, the organization of healthcare systems and the position of CBPSCs differ from country to country. In the Netherlands, the CBPSCs function independently from hospitals. In a few European countries and the USA, Canada, and Australia, that is not the case $[6,7]$. Therefore, these informal support centers may receive more cancer patients from the affiliated hospitals. Furthermore, comparative international studies are necessary on the referral, the use of, and, particularly. the possible effects of several types of CBPSCs.

\section{Word of Thanks}

The Dutch Cancer Foundation [KWF] provided a grant for these studies. Our deepest thanks to the participants in the studies and the CBPSCs staff members involved. Also, thanks to my former colleagues, Dr. AnneLoes van Staa (lecturer), Dr. Heleen van der Stege and Monique Vahedi Nikbakht-Van de Sande MSc (MVH), all part-time researchers at the Rotterdam Applied University, Centre of Expertise for Innovations in Care, Rotterdam, the Netherlands. Furthermore, we thank Rosella den Hollander and Anne van den Brom (RHAB) studying Policy and Management in Health Care, Erasmus University Rotterdam, the Netherlands at that time, for their much-appreciated contributions to the execution and reporting of the studies about the CBPSCs in the Netherlands. Finally, thanks to Rosalie Steinmann for checking the English language.

\section{References}

1. Siegel RL, KD Miller, A Jemal (2020) Cancer Statistics 2020. CA Cancer Clin J 70: 7-30.

2. Integraal Kankercentrum Nederland (IKNL) (2017) Detecteren behoefte Psychosociale zorg. Landelijke richtlijn, 
versie 2.0. (Dutch; Integral Cancer Center in the Netherlands (IKNL). http://www.oncoline.nl/

3. Holland JC (1998) Psycho-oncology. Oxford University Press, New York, USA.

4. De Haes H, Gualtherie van Wezel, R Sanderman (2017) Psychologische patiëntenzorg in de oncologie (Dutch; Psychological patient care in oncology). Gorcum B.V., Assen, the Netherlands.

5. Kreitler S (2019) Psycho-oncology for the clinician: The patient behind the disease. Springer, Cham, Switzerland.

6. Visser A, M Wildenbeest, L Nieuwenhuizen (2012) Evaluation of psychosocial support for people with cancer. Med Encount 26: 19-21.

7. Brom A van den, R den Hollander, AP Visser (2014) Onderzoek naar Inloophuizen in het buitenland voor mensen met kanker en hun naasten (Dutch; CBPSCs in foreign countries for people with cancer and their relatives). Tijdschr Psychosoc Oncol 23: 26-27.

8. Visser A (2020) Community-based psychosocial support centres for cancer patients: use, evaluation and effect. Arch. Cancer. Res Med 1: 1-9.

9. VWS, Ministry of Health, Welfare and Sport, the Netherlands (2017) Psychosociale zorg bij somatische problematiek. Werkgroep Kosten en Bekostiging. [Dutch; Psychosocial care in somatic problems. Working group Costs and Funding. https://www.tweedekamer.nl/kamerstukken / detail?id=2017D16777\&did=2017D16777

10. Visser A, W Geluk, W Breed, N van Leeuwen, $\mathrm{N}$ van, et al. (2009) De betekenis van inloophuizen voor mensen met kanker en hun naasten: ontstaan, gebruik, behoefte en waardering (Dutch; The meaning of CBPSCs for people with cancer and their relatives). Nederl Tijdschr Oncol 6: 248-255.

11. Visser AP (2021) Impact of community-based psychosocial support centres on the well-being of cancer patients: Exploration of evaluation and effects. Integr J Med Sc 8: 1-5.

12. Fishbein M, Ajzen J (2010) Prediction and changing behavior: The reasoned action approach. Psychology Press, Taylor and Francis, New York. SPPS. LUMC. 2012, Leiden, the Netherlands

13. Stege HA, van der AP Visser, CMV Vahedi Nikabakht-Van de Sande, R de Hollander, et al. (2014) Evaluatie van het bezoek aaninloophuizen door mensen met kanker en hun naasten. (Dutch; Evaluation of the visit of CBPSCs by people with cancer and their relatives). Hogeschool Rotterdam, Kenniscentrum Zorginnovatie. Rotterdam, the Netherlands.

14. Vahedi Nikbakht-Van de Sande CMV, AP Visser, HA van der Stege, A van den Brom, R den Hollander (2014) Het bezoeken van inloophuizen: een kwalitatief perspectief op de ervaringen van mensen met kanker en hun naasten (Dutch; CBPSCs: a qualitive perspective on the experiences of people with cancer and their relatives). Rotterdam: Hogeschool Rotterdam, Kenniscentrum Zorginnovatie. Rotterdam, the Netherlands.

15. Skirbekk H, L Korsvold, A Finset (2018) To support and to be supported: A qualitive study of peer support centers in cancer in Norway. Patient Educ Couns 101: 711-716.

16. Harrison JD, MJ Slomon, JM Young, Price M, J Buttow (2009) What are the unmet supportive care needs of people with cancer? A systematic review. Support. Cancer Care 17: 1117-1128.

17. IPSO and Sinzer (2018) Effectonderzoek: De maatschappelijke waarde van IPSO-inloophuizen (Dutch; Effect study: the social value of walking-in homes), IPSO, Almere, the Netherlands.

18. Ouden J, den T, Stoopman A, Verhagen (2014) De waarde van Inloophuizen. (Dutch); The value of CPSCs. RSM, Erasmus University, Rotterdam, the Netherlands.
Copyright: (02021 Dr Adriaan Visser. This is an open-access article distributed under the terms of the Creative Commons Attribution License, which permits unrestricted use, distribution, and reproduction in any medium, provided the original author and source are credited. 